\title{
BAKE HARDENING EFFECT OF THE LOW STRENGTH INTERSTITIAL FREE STEEL
}

\author{
Anh-Hoa Bui *, Minh-Hoang Nguyen, Cao-Son Nguyen \\ School of Materials Science and Engineering, Hanoi University of Science and \\ Technology, Dai Co Viet Road, Hai Ba Trung District, Hanoi, Vietnam
}

Received 26.04.2020

Accepted 17.08.2020

\begin{abstract}
This paper investigates the influence of pre-strain and temperature on the bake hardening $(\mathrm{BH})$ effect of the low strength interstitial free (IF) steel with the yield strength of $137 \mathrm{MPa}$. The tensile specimens were pre-strained to 2-4-6\% at room temperature followed by baking at temperatures of $150-200-250{ }^{\circ} \mathrm{C}$ for 20 minutes. The $\mathrm{BH}$ strength was determined by a standard procedure based on the difference between the lower yield strength of the baked specimen and the flow stress of the initial one. The microstructure of the IF steels was characterized by optical microscopy and scanning electron microscopy for the purpose of explaining the BH effect. All the initial and baked steels show a microstructure that includes the ferrite phase, of an average grains size of $45 \mu \mathrm{m}$. This observation was consistent with the mechanical properties of the initial steel. The $\mathrm{BH}$ strengths have been achieved from 12 to $35 \mathrm{MPa}$, in which the maximum value was found for the specimen that pre-strained to $6 \%$ and baked at 200 ${ }^{\circ} \mathrm{C}$. The $\mathrm{BH}$ strengths increased with increasing the pre-strain, but slightly decreased when the baking temperature was $250{ }^{\circ} \mathrm{C}$. This mechanism is attributed to pinning of dislocation by carbon solute atoms during the baking process, and the $\mathrm{BH}$ strength was correlated with grain boundary segregation.
\end{abstract}

Keywords: Bake hardening, Microstructure, Interstitial free steel, Dislocation.

\section{Introduction}

Steels that harden during drying are very promising materials that make it possible to combine low yield strength with substantial hardening after forging and drying of the lacquer coating of the finished car [1]. The steel sheets used for the car's inner and outer panels (door, hood, and roof) should have high strength and good formability. Thus, interstitial free (IF) steel can be widely applied in the automotive industry for its excellent forming characteristics and an increased strength that is 
obtained due to paint baking of the final product [2-4]. IF steels can be classified by the value of tensile strength: low IF steel and high strength IF steel containing many more alloying elements, which also cause some metallurgical problems. For example, leading to severe clogging of submerged entry nozzle (SEN) during continuous casting [5], or leading to the formation of surface oxidation and segregation and subsequently may have a decreased effect on coating quality [2]. Since the low strength IF steel has good formability but does not have enough strength for dent resistance capacities, conventional paint baking operation of the low IF steel becomes very important to fulfill the requirements of thinner sheet steel for making automotive panels. The strength improvement resulting from this process can help the manufacturers to reduce the car weight and environmental pollution. Bake hardening $(\mathrm{BH})$ is a phenomenon occurring in steel corresponding to an increase of the flow stress after a pre-strain followed by heating within a specific temperature range [6]. This phenomenon is essentially a strain aging process resulting from the interaction between interstitial carbon atoms dissolved in the matrix and the dislocations generated during forming operations [4].

Recently, the $\mathrm{BH}$ phenomenon of steel has become not complicated to understand. Much research has been carried out to clarify the dependence of its magnitude on the chemical composition, deformation, and heat treatment. Interstitial free steel is considered suitable for a $\mathrm{BH}$ grade because of its good formability processing and easier control of the solute $\mathrm{C}$ to the desired level [7]. According to Storotreva et al., the $\mathrm{BH}$ effect was based on the ability of free $\mathrm{C}$ atoms to fix mobile dislocations in ferrite at elevate temperatures, so this makes it possible to harden stamped parts in the process of drying the paint [1]. Some research has been conducted to clarify the BH effect of IF steels [4, 7-9]. Several mechanisms have been proposed for the strain-aging phenomenon of steels that contain solute $\mathrm{C}$ and $\mathrm{N}$; however, the major mechanism currently accepted is dislocation pinning by solute $\mathrm{C}$ or $\mathrm{N}$ atoms and precipitation hardening $[1,4]$.

$\mathrm{BH}$ phenomenon of high strength IF steel has been studied by earlier research works [1, 6-11]. As far as the IF steels are concerned, most research has been concerned with the formability improvement but keeping high strength because this confers a high dent resistance for the steel. In this study, BH effect of low strength IF steel has been investigated and discussed in the correlation with the microstructure and the mechanical properties of the initial steel.

\section{Experimental}

The IF steel specimens, chemical compositions of which are listed in Table 1, were prepared from a commercial $0.8 \mathrm{~mm}$ thickness sheet. The tensile specimens (gauge length $30 \mathrm{~mm}$ and width $6 \mathrm{~mm}$ ) were cut in accordance with the Standard ASTM E8, as in Fig. 1. For the investigation of the BH effect, the specimens were pre-strained to 2-4$6 \%$ and then baked at a temperature of $150-200-250{ }^{\circ} \mathrm{C}$ for 20 minutes in a resistance furnace. The initial and baked specimens were tensile tested using an MTS 809 machine. Finally, the BH strength was calculated as the difference in the lower yield strength of the baked steel and flow stress of the initial one.

Table 1. Chemical compositions of the initial steel (\% mass).

\begin{tabular}{llllll}
\hline $\mathrm{C}$ & $\mathrm{Mn}$ & $\mathrm{Si}$ & $\mathrm{P}$ & $\mathrm{S}$ & $\mathrm{Ti}$ \\
\hline 0.0025 & 0.0808 & 0.0155 & 0.0076 & 0.0066 & 0.0275 \\
\hline
\end{tabular}


A longitudinal cross-section of the initial specimen was cut for microstructural observation by using optical microscopy (Axiovert 40MAT) and scanning electron microscopy (Hitachi SU3500). The grain size was measured by the linear intercept approach over the optical micrograph.

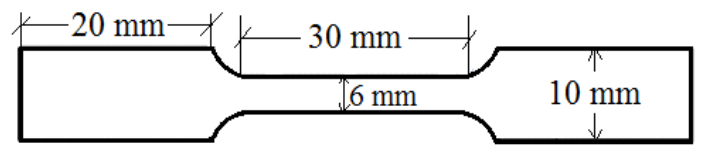

Fig. 1. Dimensions of the tensile specimen.

\section{Results and discussion}

\section{Mechanical properties and microstructure of the initial IF steel}

Ultimate tensile strength (UTS), yield strength (YS), and elongation (EL) of the initial IF steel are given in table 2. The strength of the initial steel was quite low because the steel contained a small amount of strengthening elements such as $\mathrm{Si}$ and $\mathrm{Mn}$. In common steel, the content of these elements can increase to improve the strengths because Mn plays a role as solution strengthening [12]; and $\mathrm{Si}$, as a substitution solute in ferrite has remarkably effective in generating dislocation during quasi-static tensile deformation and thereby increases dislocation density [13]. From the viewpoint of microstructure and mechanical properties, those alloying elements improve hardenability by building up bainite and martensite microstructures, rather than polygonal ferrite microstructures during cooling [2]. Furthermore, a severe requirement for the surface quality may also make it difficult to apply higher strength steels. According to Dehghani et al., the YS of the steels should be as low as possible to avoid the aforementioned defects in press forming, although tensile ductility cannot be the criteria for the deep drawability of steel [14]. Thus, it is necessary to optimize the processing conditions to increase the ductility because the microstructure with high dislocation density increases the strength significantly. The YS of the initial steel was $137 \mathrm{MPa}$, indicates that the strength of the present study was lower than that of the automotive IF steels, which exhibit typically 200-280 MPa of YS and 30-47\% of EL [15-17]. The YS after baking is usually used to evaluate the dent resistance of the steel; therefore, $\mathrm{BH}$ response is essential for the products which are made of the low strength IF steel when the paint is baked.

Table 2. Strength and elongation of the initial specimen.

\begin{tabular}{lll}
\hline $\operatorname{UTS}(\mathrm{MPa})$ & YS $(\mathrm{MPa})$ & EL $(\%)$ \\
\hline 205 & 137 & 47 \\
\hline
\end{tabular}

Fig. 2 shows the optical micrograph of the initial steel, in which recrystallized grains of the ferrite phase can be observed. The average grain size was estimated as about $45 \mu \mathrm{m}$ - quite coarsen grains in comparison with higher strength IF steels. This microstructure was consistent with the high ductility and low strength of the initial steel, as listed in Table 2. According to the previous papers, the grain size has a slight effect on solute $\mathrm{C}$ content in the ferrite but plays an important role in the density of free 
dislocations during pre-straining [10, 18]. Therefore, the strength of all the baked steel was predicted to increase because the pre-straining caused a higher dislocation density that increased with increasing the strain rate.

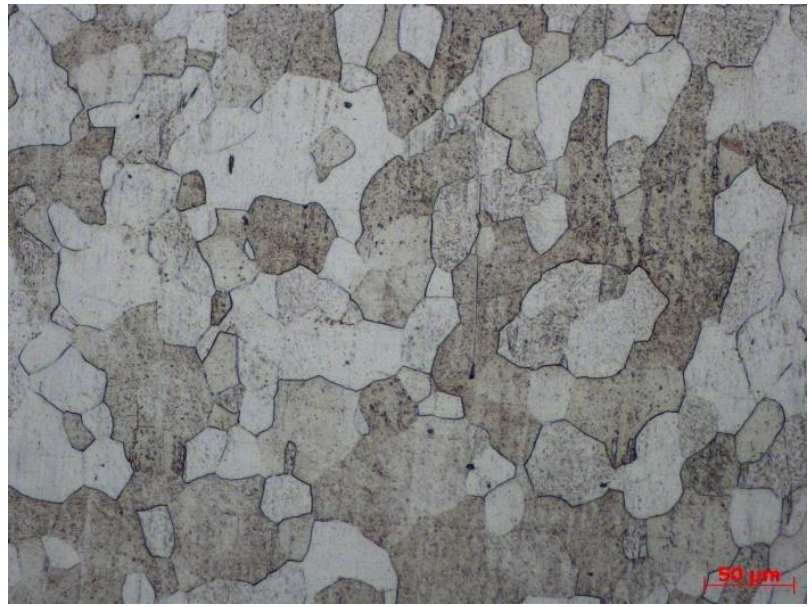

Fig. 2. Optical micrograph of the initial steel.

Effect of pre-strain and baking temperature on the BH strength

Table 3 shows the mechanical properties of the baked specimens. It is seen that all the baked steel had higher strengths (i.e. YS and UTS) than the initial one. Because the higher YS significantly promotes the surface deflections, it is recommended to apply the steel with YS less than $240 \mathrm{MPa}$ [17]. Thus, the present steel with the YS of 137 $\mathrm{MPa}$ would be a promising material for the application of deep drawability. The prestraining followed by baking caused an increase in the subsequent YS from 43 to 88 $\mathrm{MPa}$. In simplicity, this result can be explained that the steel has been hardened due to the pre-straining, after which the residual stress in the steel affected the mechanical properties. However, Bhagat et al. applied the Cottrell theory and explained that the rise in YS was associated with the formation of solute atmospheres and saturation of stress field around the dislocations which formed during the deformation [7]. More solute $\mathrm{C}$ in the ferrite increases the strength of the steel, but may cause the stretcher - strain pattern due to local yielding during the press forming; as a result, adding $\mathrm{Ti}$ and/or $\mathrm{Nb}$ as carbides of nitrides is the effective way to reduce the amount of solute $\mathrm{C}$ and $\mathrm{N}$ in the steels $[17,19]$.

Table 3. Mechanical properties of the baked steels.

\begin{tabular}{llll|lll|lll}
\hline Pre-strain $(\%)$ & 2 & & & 4 & & & 6 & \\
\hline $\begin{array}{l}\text { Baking temperature } \\
\left({ }^{\circ} \mathrm{C}\right)\end{array}$ & 150 & 200 & 250 & 150 & 200 & 250 & 150 & 200 & 250 \\
YS (MPa) & 180 & 188 & 186 & 195 & 208 & 205 & 212 & 225 & 220 \\
UTS (MPa) & 211 & 220 & 225 & 227 & 236 & 246 & 241 & 260 & 265 \\
EL $(\%)$ & 46 & 46 & 47 & 45 & 45 & 46 & 43 & 43 & 44 \\
\hline
\end{tabular}




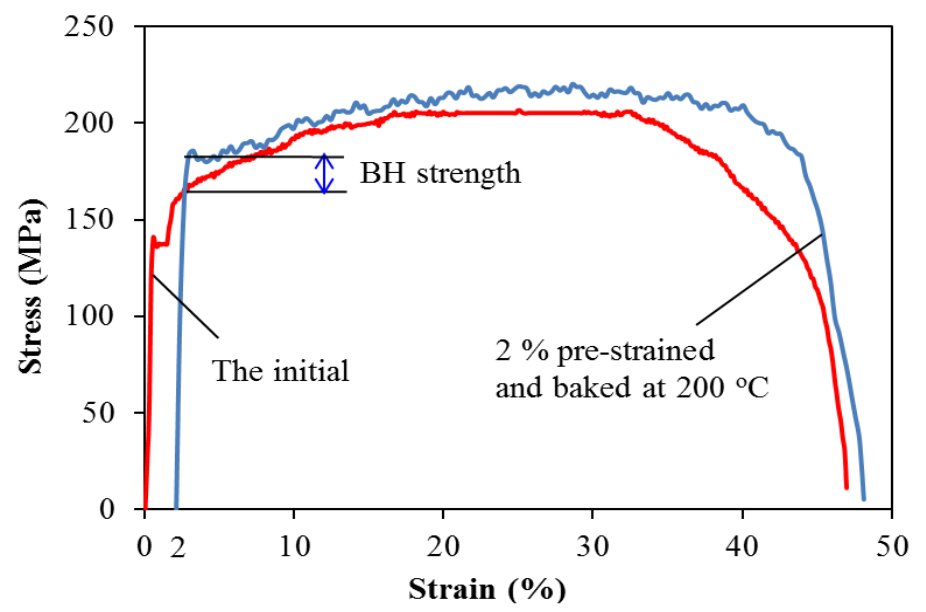

Fig. 3. BH strength determination of the specimen pre-strained to $2 \%$ and baked at $200^{\circ} \mathrm{C}$.

Fig. 3 shows an example of the BH strength determination for the specimen that pre-strained to $2 \%$ and baked at $200{ }^{\circ} \mathrm{C}$. In the strain-stress curves of the specimens, the lower yield point of the baked specimen was $20 \mathrm{MPa}$ higher than the flow stress of the initial one. Similarly, the BH strengths of all the bake specimens were calculated. The effect of the $\mathrm{BH}$ strengths on the pre-strain and the baking temperature is presented in Fig. 4, where the $\mathrm{BH}$ strengths were seen to be in the range of 12 to $35 \mathrm{MPa}$. It is evident that the $\mathrm{BH}$ strengths increased with the pre-strain, but decreased when the baking temperature increased to $250{ }^{\circ} \mathrm{C}$. These results are in agreement with Dehghani et al. [14] and Kvackaj et al. [20], who found the classical BH magnitudes being from 30 up to $60 \mathrm{MPa}$ after a few percent of pre-strain and heating at around $170{ }^{\circ} \mathrm{C}$ during 20 minutes.

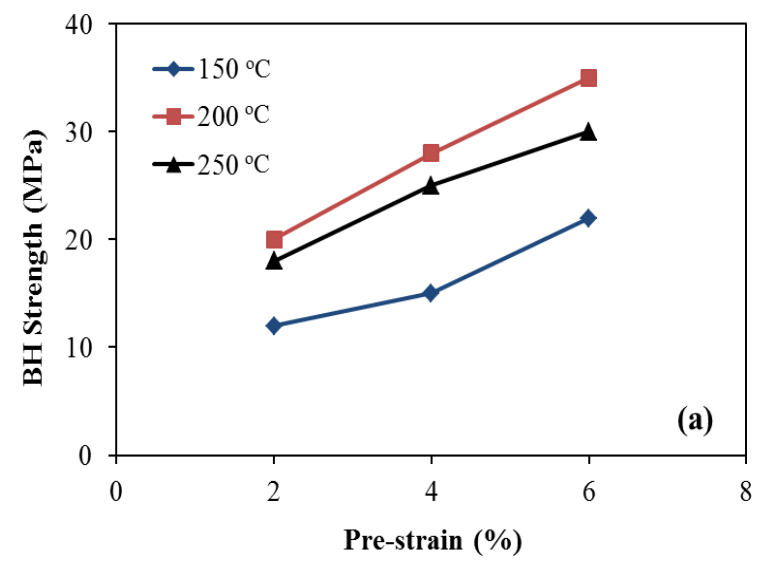




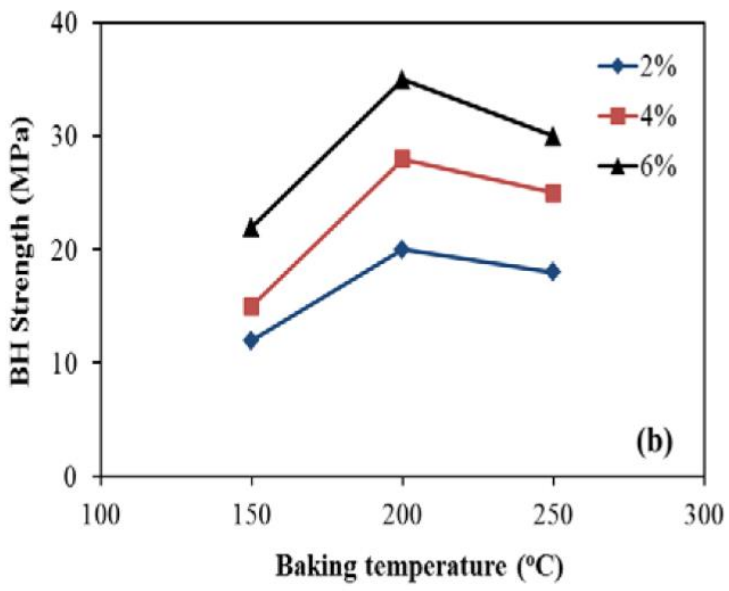

Fig. 4. Effect of pre-strain (a) and baking temperature (b) on the BH strength

\section{Discussion}

In spite of the fact that the grain size have no clear effect on the $\mathrm{BH}$ phenonmenon, Antoine et al. studied the effect of the microstructure on the strainhardening behavior of a Ti-IF steel grades and concluded that decreasing the grain sizes resulted in higher dislocation densities, which caused the remained stress increment in all the specimens after work hardening [9]. This conclusion consolidated the explanation of that the residual stress increased the strengths of the baked steels as listed in table 3. Concerning the dependence of yield stress on microstructural parameters, the Hall-Petch relationship is usually used $[10,15,21]$ :

$$
\sigma_{y}=\sigma_{o}+k_{y} d^{-0.5}
$$

Where $\sigma_{\mathrm{o}}$ is the internal stress, $\mathrm{d}$ the ferrite grain size and $\mathrm{k}_{\mathrm{y}}$ a constant. The term $\sigma_{o}$ includes the contribution from friction stress, solid solution effect, strengthening from precipitation and dislocation hardening. According to Takeda et al., the internal stress almost converges on one similar value around $60 \mathrm{MPa}$; the Hall-Petch coefficient of ferritic iron is approximately $100 \mathrm{MPa} . \mu \mathrm{m}^{0.5}$ and increases with increasing the $\mathrm{C}$ content [22]:

$$
k_{y}=100+120 \times\left[C_{p p m}\right]^{0.31}
$$

Thus, the calculated $\mathrm{k}_{\mathrm{y}}$ and $\sigma_{\mathrm{y}}$ are $455 \mathrm{MPa} . \mu \mathrm{m}^{0.5}$ and $128 \mathrm{MPa}$ for the initial IF steel of the present study, respectively. The value of $\sigma_{y}$ is a bit different from the tensile tested YS of $137 \mathrm{MPa}$. In this work, the microstructures of all the baked specimens were also investigated, but it was found almost the same as the initial steel. The fact that the average grain size was not changed indicates that the value of $\mathrm{k}_{\mathrm{y}}$ should have varied with the pre-strain. In an agreement, Ono et al. studied the BH effect of IF steel and 
concluded that the $\mathrm{k}_{\mathrm{y}}$ increased little at the beginning stage of baking, while increases drastically during the end of the process, then becomes saturated at around 500 $\mathrm{MPa} . \mu \mathrm{m}^{0.5}$ [10]. This conclusion seems to be derived from the grain boundary segregation of $\mathrm{C}$ atoms, i.e. the Hall-Petch coefficient $\left(\mathrm{k}_{\mathrm{y}}\right)$ increased with grain boundary segregation [23]. An SEM image of the steel pre-strained to $6 \%$ and baked at $200{ }^{\circ} \mathrm{C}$ is shown in Fig. 5, where the grain boundaries can be seen clearly and the contrast between grains is due to different $\mathrm{C}$ compositions.

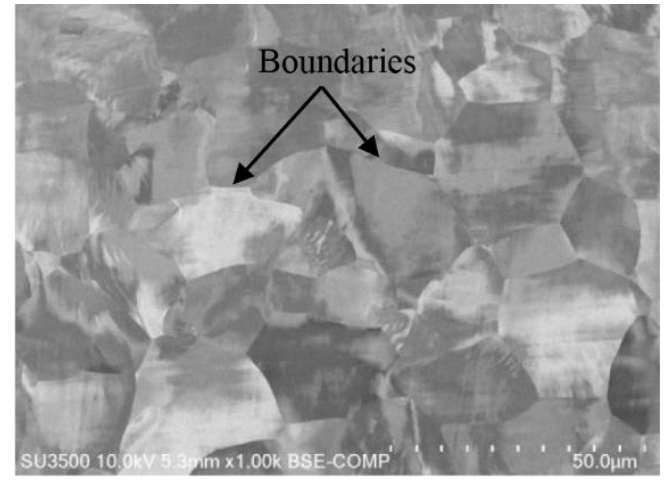

Fig. 5. SEM micrograph of the steel pre-strained to $6 \%$ and baked at $200^{\circ} \mathrm{C}$

The mechanism of the $\mathrm{BH}$ effect has been discussed in several research papers, after which $\mathrm{BH}$ steel must contain a certain minimum amount of solute $\mathrm{C}$ that is responsible for the strength increment as a result of interstitial atom segregation to dislocations $[1,14,24]$. The lower level of solute $\mathrm{C}$, the less $\mathrm{BH}$ strength is gained. Therefore, the required amount of solute $\mathrm{C}$ to have sufficient susceptibility for the $\mathrm{BH}$ effect has been reported 5 to $15 \mathrm{ppm}$ [14]. Due to this reason, there is a need for an optimum amount of solutes in the steel. Baker et al. proposed two stages of strengthening, including that the first stage is a result of dislocation (Cottrell) locking by solute $\mathrm{C}$ atoms and the latter results from the continued segregation of solute atoms to the saturated atmosphere [24]. When the present steels were baked in the temperature of $150-250{ }^{\circ} \mathrm{C}$, the dissolved $\mathrm{C}$ migrates to pin any free dislocations introduced during the pre-strain. Das et al. reported that a large pre-strain would leave more free dislocations, and hence reduce the $\mathrm{BH}$ strength if the aging conditions are insufficient to ensure the pining of all available dislocation [25]. The BH strengths in Fig. 4a did not decrease with increasing the pre-strain, indicating that the dissolution locking was sufficient. $\mathrm{BH}$ response should also increase with increasing the amount of solute $\mathrm{C}$ in steel. This is because of the fact that with increasing solute $\mathrm{C}$ in steel, more solute $\mathrm{C}$ is available to pin mobile dislocations, and the formation of clusters will occur more rapidly [14]. As seen in Fig. 4b, the BH strengths decreased in all the specimens pre-strained and baked at $250{ }^{\circ} \mathrm{C}$. It could be attributed to a reduction of solute $\mathrm{C}$ at a high baking temperature as an explanation of Kuang et al., who found the BH strength reduce with decreasing the solute $\mathrm{C}$ content in the interior [18]; and Baker et al. who concluded that the solute $\mathrm{C}$ decreased when the baking temperature increased from 100 to $200{ }^{\circ} \mathrm{C}$ [24]. The higher the baking temperature, the more solute $\mathrm{C}$ atoms will diffuse to grain boundaries, 
resulting in decreasing the $\mathrm{C}$ atoms inside the grains and caused a reduction of the strength.

\section{Conclusions}

$\mathrm{BH}$ effect of a low strength IF steel sheet has been investigated using the tensile testing and microstructural observation. The tensile specimens were cut from the initial steel, pre-strained to 2-4-6\%, and then baked at a temperature of $150-200-250{ }^{\circ} \mathrm{C}$ for 20 minutes. The main conclusions are as follows:

(1) Microstructure, including the ferrite phase, of which grain size was about 45 $\mu \mathrm{m}$ on average, was found almost the same in all the initial and baking steels. The HallPetch coefficient $\left(\mathrm{k}_{\mathrm{y}}\right)$ of the initial steel was calculated as a value of $455 \mathrm{MPa} . \mu \mathrm{m}^{0.5}$, which was considered to increase with the solute $\mathrm{C}$ after the pre-straining and baking the steel.

(2) All the baked steels had an increment of the strength due to the increase in density of dislocations after the pre-strain. The YS values stayed in the range of 180 to $225 \mathrm{MPa}$, which was very high in comparison with the initial steel. The improved strengths would contribute to the better dent resistance of the final products.

(3) Despite the ultra-low C content, the BH effect of this low strength IF steel was the same as for higher strength steels. The $\mathrm{BH}$ strengths were obtained in the range of 12 to $35 \mathrm{MPa}$, which maximum value was for the steel pre-strained to $6 \%$ and baked at $200{ }^{\circ} \mathrm{C}$; they increased with the pre-strain, but slightly decreased when the baking temperature increased to $250{ }^{\circ} \mathrm{C}$.

\section{Acknowledgments}

This research is funded by Hanoi University of Science and Technology (HUST) under grant number T2018-PC-224.

\section{References}

[1] L.M. Storozheva: Met Sci Heat Treat, 43 (2001) 336-343.

[2] S.I. Kim, and Y. Lee: Met Mater Int, 18 (2012) 735-744.

[3] P. Balke, J.Th.M. De Hosson: Scr Mater, 44 (2001) 461-466.

[4] A.K. De, S. Vandeputte, and B.C. De Cooman: J Mater Eng Perform, 10 (2001) 567-575.

[5] J.H. Lee, M.H. Kang, S.K. Kim, J.H. Kim, M.S. Kim, and Y.B. Kang: ISIJ Int, 59 (2019) 749-758.

[6] S. Thuillier, S.L. Zang, J. Troufflard, P.Y. Manach, and A. Jegat: Metals, 8 (2018) 594-610.

[7] A.N. Bhagat, S.J. Baek, and H.C. Lee: ISIJ Int, 48 (2008) 1781-1787.

[8] M.H. Hong, N.H. Cho, S.I. Kim, O.J. Kwon, S.H. Lim, and W.J. Moon: Met Mater Int, 16 (2010) 883-890.

[9] P. Antoine, S. Vandeputte, and J.B. Vogt: ISIJ Int, 45 (2005) 399-404.

[10] Y. Ono, Y. Funakawa, K. Okuda, K. Seto, N. Ebisawa, K. Inoue, and Y. Nagai: ISIJ Int, 57 (2017) 1273-1281.

[11] W.C. Jeong: Mater Lett, 61 (2007) 2579-2583.

[12] M. Davari, M. Mansouri: Metall Mater Eng, 23 (2017), 143-152.

[13] V. Yadav, A.K. Singh, and G. Sahoo: J Met Mater Miner, 28 (2018) 16-21.

[14] K. Dehghani, and J.J. Jonas: Metall Mater Trans A, 31 (2000) 1375-1384. 
[15] A.H. Bui, H. Le: Acta Metall Slovaca, 22 (2016) 35-43.

[16] J. Galan, L. Samek, P. Verleysen, V. Verbeken, Y. Houbaert: Rev de Metal, 48 (2012) 118-131.

[17] M. Takahashi: ISIJ Int, 55 (2015) 79-88.

[18] C.F. Kuang, J. Wang, J. Li, S.G. Zhang, H.F. Liu, H.L. Yang: J Iron Steel Res Int, 22 (2015) 163-170.

[19] M. Jecmenica, R. Stefanovic, G. Vukicevic, Metall Mater Eng, 21 (2015), 183193.

[20] T. Kvackaj, I. Mamuzic: Metalurgija, 45 (2006) 51-55.

[21] R. Matoba, N. Nakada, Y. Futamura, T. Tsuchiyama, S. Takasi: Tetsu-toHagane, 93 (2007) 513-517.

[22] K. Takeda, N. Nakada, T. Tsuchiyama, and S. Takaki: ISIJ Int, 48 (2008) $1122-$ 1125 .

[23] S. Akari, K. Mashima, T. Masumura, T. Tsuchiyama, S. Takaki, T. Ohmura: Scr Mater, 169 (2019) 38-41.

[24] L.J. Baker, J.D. Parker, and S.R. Daniel: Mater Sci Technol, 18 (2002) 541-547.

[25] S. Das, S.B. Singh, O.N. Mohanty, and H.K.D.H. Bhadeshia: Mater Sci Technol, 24 (2008) 107-111.

\section{(c) (†) Creative Commons License}

This work is licensed under a Creative Commons Attribution 4.0 International License. 